\title{
Spectrofluorimetric Determination of Zinc in Human Hair by Using Ortho Hydroxy Acetophenone Hydrazone Doped in Sol-Gel Matrix
}

\author{
Badr A. El-Sayed ${ }^{1 *}$, Sally G. Sedeek ${ }^{2}$, Mohamed M. Abo-Aly ${ }^{2}$, Mohamed S. Attia ${ }^{2}$ and Dina Y. \\ Sabry $^{2}$ \\ ${ }^{1}$ Chemistry Department, Faculty of Science, Al Azhar University, Cairo, Egypt, \\ ${ }^{2}$ Chemistry Department, Faculty of Science, Ain Shams University, Cairo, Egypt
}

\section{A R T I C L E I N F O}

Article history:

Received 17 June 2015

Accepted 05 August 2015

Keywords:

Fluorescent enhancement;

Schiff's bases;

Sol-gel;

Chemosensor;

Zinc.

\begin{abstract}
A B S T R A C T
A novel Schiff base (o- hydroxy acetophenone hydrazone) was synthesized via condensation of 2-OH acetophenone and hydrazine monohydrate. Photoluminescence characteristics of the ligand were investigated in different solvents including acetonitrile (AC), ethanol (ETOH), dimethyl formamide (DMF) and dimethyl sulphoxide (DMSO). The ligand was found to have higher emission intensity in DMSO solution. The Chemosensor was synthesized for detecting Zinc ion in human hair for males and females with age range (15y $31 y)$. The assessment of zinc ion from the remarkable enhancement of the luminescence intensity at $425 \mathrm{~nm}$ of the ligand (o-hydroxyacetophenone hydrazone) doped in sol-gel matrix by various concentrations of the zinc ion. The calibration plot was achieved over the concentration range $1.0 \times 10^{-8}-2.0 \times 10^{-4}$ mol L ${ }^{-1}$ of zinc ion with a correlation coefficient of 0.993 and a detection limit of $3.72 \times 10^{-9} \mathrm{~mol} \mathrm{~L}^{-1}$. The sensor showed excellent selectivity toward $\mathrm{Zn}^{2+}$ ion with respect to common coexisting cations. The proposed fluorescence sensor was successfully applied to detect $\mathrm{Zn}^{2+}$ ion in human hair for both females and males.
\end{abstract}

\section{Introduction}

Schiff's bases are important class of compounds, due to their variety of applications including biological, clinical, analytical and industrial in addition to their important roles in catalysis and organic synthesis ${ }^{[1]}$. Hydrazones, $\quad \mathrm{RR}^{\prime} \mathrm{C}=\mathrm{N}-\mathrm{NR}$ "R", were used as intermediates in synthesis, as functional groups in metal carbonyls and in organic compounds ${ }^{[2]}$. Furthermore, hydrazones exhibit physiological activities in the treatment of several diseases such as tuberculosis. Zinc ion plays many roles in the body which has a special and practical importance in the growing organism: helping build cells, keeping hormones in check, assisting the absorption of various other vitamins and giving the body a helping hand with protein use. All of these actions are essential for hair growth and maintenance. $\mathrm{Zn}^{2+}$ ion is an essential metal cation of exceptional biologic and public health importance ${ }^{[3]}$, where it has multiple roles in both extra-and intra-cellular functions, for example $\mathrm{Zn}^{2+}$ ion is known to be indispensable to growth, development and transmission of the genetic message ${ }^{[4]}$. The negative effect of $\mathrm{Zn}^{2+}$ ion appeared when its abnormal concentration existed in the natural and biological

\footnotetext{
* Corresponding author.

E-mail address: badrelsayed@gmail.com
}

systems. For example, in the environment an excessive concentration of zinc ion may reduce the soil microbial activity resulting in the phytotoxic effect ${ }^{[5]}$. Moreover, it occurs commonly as an agriculture and food waste product in the environment. In the biological system, it is also known that disorders of zinc metabolism are closely associated with many severe neurological diseases such as Alzheimar's disease (AD). Hair is composed of proteins, lipids, water, and small amounts of trace elements. All proteins in animal and human bodies are built from permutations of amino acid molecules in a polypeptide string. The polypeptide chains of protein keratin are organized into filaments in hair cells. Hair is one of the most difficult proteins to digest or solubilize. Among the most common dissolving procedures for hair is acidic, alkaline, and enzymatic hydrolysis. For the analysis of hair, the solid samples are transferred by solubilization via digestion into a liquid phase ${ }^{[6]}$. Research during the past three decades suggests that the relationship between hair element concentrations and human health is a complex process related to exposure, absorption, and tissue distribution of essential and toxic elements. Follow-up blood testing or provocative urine testing is useful to confirm hair element findings. Blood provides information about what the body has recently 
absorbed (hours to days in some cases weeks).

Blood levels are largely independent of tissue deposition. Blood levels vary according to the actual component analyzed (plasma, serum, RBC). They can be transient in nature, and are subject to the body's homeostatic mechanisms to maintain levels within narrow range ${ }^{[7]}$. In the present work a new synthesized $o$-hydroxy acetophenone hydrazone was used as a nano optical sensor for determination of zinc levels in human hair for women and men by the enhancement of the luminescence intensity of $o$-hydroxy acetophenone hydrazone by different zinc ion concentrations in dimethyl sulphoxide (DMSO).

\section{Materials and methods}

\section{Chemicals and reagents}

All chemicals used are analytical reagent of higher grade. Tetraethyoxy silane (TEOS) was supplied from Aldrich and also all solvents as Absolute ethanol (EtOH), Dimethyl sulphoxide (DMSO) were purchased from Aldrich and they were used as received. A stock solution of $\mathrm{Zn}^{2+}$ ion $\left(1.0 \times 10^{-2} \mathrm{M}\right)$ was prepared by dissolving $0.2974 \mathrm{~g} \mathrm{Zn}\left(\mathrm{NO}_{3}\right)_{2}-6 \mathrm{H}_{2} \mathrm{O}$ in exactly $100 \mathrm{~mL}$ of deionized water and standardizing with EDTA ${ }^{[8]}$.

\section{Physical Methods of Measurements}

All luminescence measurements were recorded with a Meslo- PN (222-263000) z Thermo Scientific Lumina fluorescence Spectrometer in the range $(220-750 \mathrm{~nm})$. The absorption spectra of the samples were measured in the range of $190-900 \mathrm{~nm}$ with Thremo UV-Visible double-beam spectrophotometer. The $\mathrm{pH}$ was measured using JAN-WAY $3330 \mathrm{PH}$ meter. TEM image was taken on a JEOL JEM-1230 available at Ain Shams University. JEOL JEM-1230 is a high performance, high contrast, 40-120 kV Transmission Electron Microscope with excellent imaging capabilities. The FTIR spectra were measured as $\mathrm{KBr}$ pellets on the Mattson 1000 FTIR spectrophotometer.

\section{General procedures}

1. Synthesis of $o-\mathrm{OH}$ acetophenone Hydrazone as a Ligand

Orthohydroxy acetophenone hydrazone (ligand) was prepared by the slow dropwise of $(0.05 \mathrm{~mol}, 6.05 \mathrm{~g}) o^{-}$ hydroxy acetophenone dissolved in $50 \mathrm{~mL}$ of absolute ethanol to hydrazine monohydrate $(0.025 \mathrm{~mol}, 2.5 \mathrm{~g})$ dissolved in $50 \mathrm{~mL}$ of absolute ethanol. The reaction mixture was heated under reflux for $5 \mathrm{~h}$, and then the mixture was left at room temperature to coagulate until the solid product was formed. The formed product was filtered off under suction and recrystallized from ethanol, yield $2 \mathrm{~g}^{[9]}$.

\section{Synthesis of $o-\mathrm{OH}$ acetophenone Hydrazone doped} in Sol-gel Matrix

A mixture consisting of Tetraethoxysilane (TEOS), $\mathrm{C}_{2} \mathrm{H}_{5} \mathrm{OH}$ and $\mathrm{H}_{2} \mathrm{O}$ in a molar ratio of 5:5:1 was refluxed for $1 \mathrm{~h}$ to give precursor sol solution using a few drops of diluted $\mathrm{HCl}$ solution as a catalyst. Subsequently, appropriate amount of the $\boldsymbol{o}$-hydroxy acetophenone hydrazone $(0.02 \mathrm{~g})$ dissolved in $10 \mathrm{~mL}$ DMSO and the precursor solution were mixed and stirred together for 15 min until the mixture became homogeneous. The obtained ligand dispersed sol solution was dried into oven at $240^{\circ}$ $\mathrm{C}$ for $10 \mathrm{~min}$ to give solidified and transparent composite sample ${ }^{[10]}$

\section{Preparation of Hair Sample}

Samples of hair (10-20 mm in length and weighing about $500 \mathrm{mg}$ ) were taken close to the skin from the same region of the nape of the neck for each male and female in the age range $(15 y-31 y)$; these were then cut into lengths of 1-2 $\mathrm{mm}$ with scissors. After exhaustive washing with acetone, detergent solution (sodium lauryl sulphate, $100 \mathrm{~g} / \mathrm{l}$ ), and distilled water in sequence, followed by a final rinsing in acetone and carbon tetrachloride in order to remove lipids and dust particles [11]. The hair samples were air dried between filter paper. In the procedure about $0.1 \mathrm{~g}$ of the hair sample was digested in a $15 \mathrm{~mL}$ test tube with $0.2 \mathrm{~mL} 10 \mathrm{M} \mathrm{NaOH}$ over a hot bath at $90{ }^{\circ} \mathrm{C}$ for $15 \mathrm{~min}$. After cooling, the digest was made up to $25 \mathrm{ml}$ with glass-distilled water and analyzed for zinc ion ${ }^{[12]}$.

\section{Results and discussion}

\section{Characterization of the o-OH acetophenone Hydrazone}

The structure of the synthesized $\boldsymbol{o}$-hydroxy acetophenone hydrazone (Ligand) was investigated using FTIR and elemental analyses. The morphology of ligand doped in sol-gel matrix was investigated by TEM Scheme 1 .

Analysis of the IR spectra of o-Acetophenone hydrazone

The IR spectra in the range $4000-400 \mathrm{~cm}^{-1}$ of the hydrazone ligand is shown in Fig. 1 The assignment of the ligand bands was reported in the Table 1.

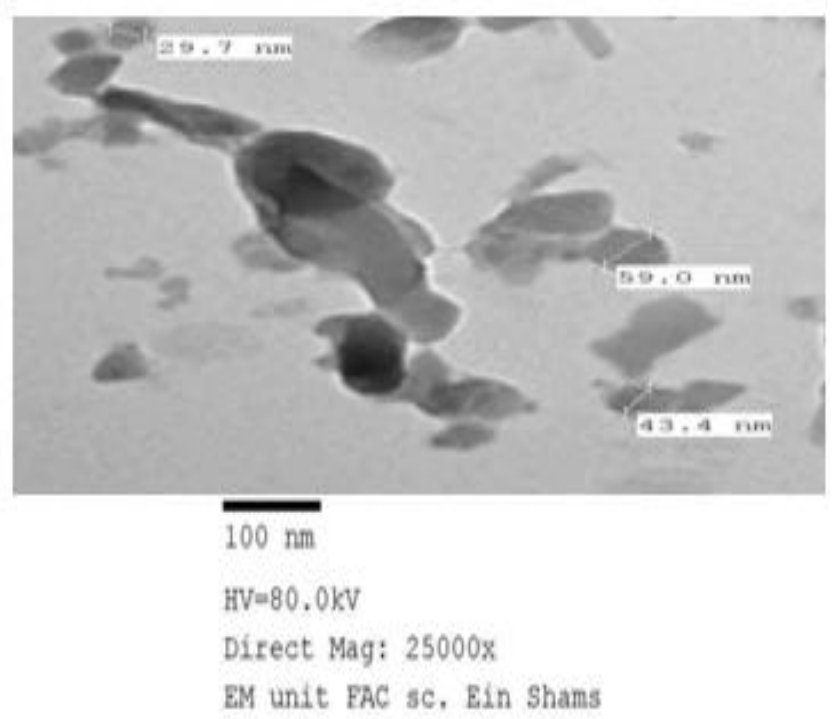

Scheme 1: TEM image of nano optical sensor o-OH acetophenone hydrazone (Average size of nano particle $44 \pm 2$ ) 


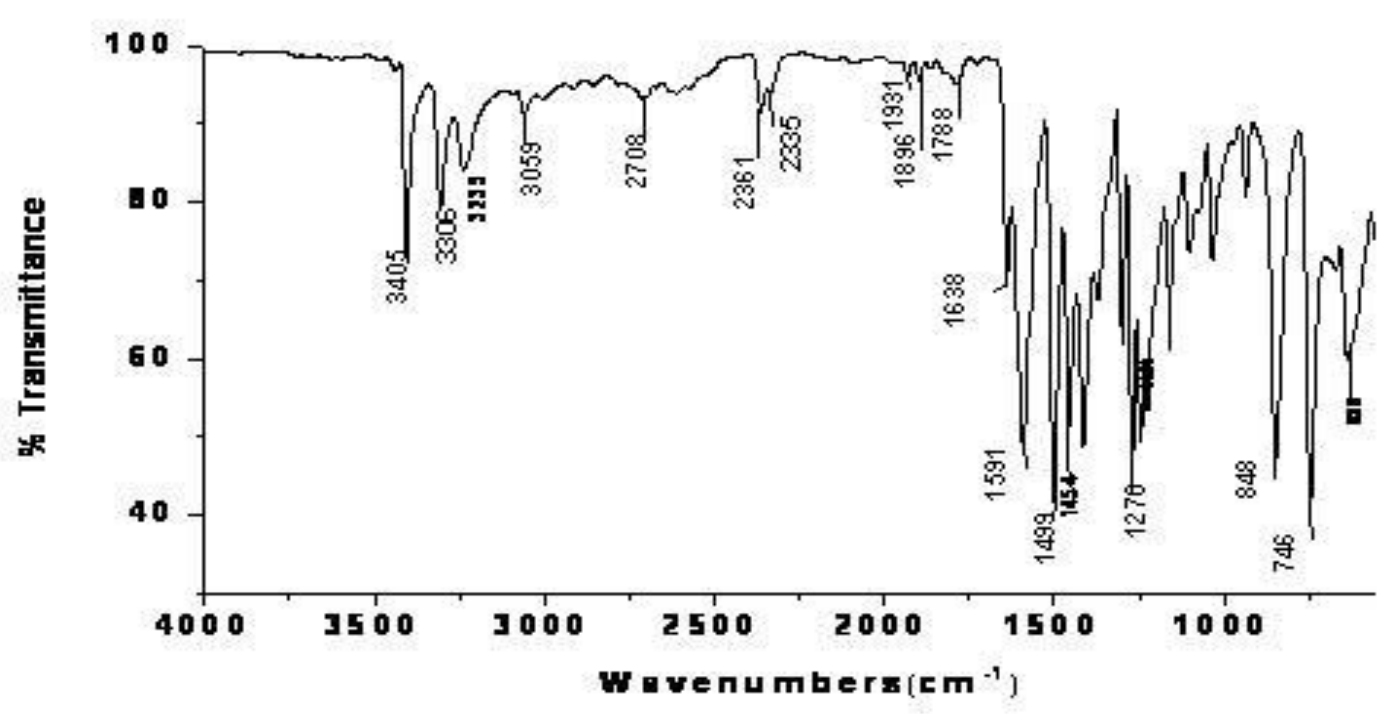

Fig. 1: Infra-red spectra of o-hydroxy acetophenone hydrazone.

Table 1: FTIR spectra of the Ligand o-OH acetophenone hydrazone.

\begin{tabular}{|c|c|}
\hline Ligand bands $\left(\mathrm{cm}^{-1}\right)$ & Assignment \\
\hline 3405 & $v_{(\mathrm{OH})}$ \\
\hline 3239 & $v_{\mathrm{a}(\mathrm{NH} 2)}$ \\
\hline 3059 & $v_{\mathrm{C}-\mathrm{H}}$ \\
\hline 1638 & $v_{(\mathrm{C}=\mathrm{N})}$ \\
\hline 1270 & $v_{(\mathrm{C}-\mathrm{O})}$ \\
\hline
\end{tabular}

\section{Assignment of $o$-OH Acetophenone hydrazone}

The structure of $\boldsymbol{o}$-hydroxy acetophenone hydrazone Scheme 2 has been confirmed by FTIR technique. The most characteristic vibrational bands observed in the spectrum of the ligand are as follows: The broad band observed at $3405 \mathrm{~cm}^{-1}$ was attributed to $\mathrm{U}(\mathrm{OH})$ stretching. The absorption band observed at $3239 \mathrm{~cm}^{-1}$ was assigned to $\mathrm{U}\left(\mathrm{NH}_{2}\right)$ stretching vibration. The absorption band observed at $3059 \mathrm{~cm}^{-1}$ was due to the $\mathrm{C}-\mathrm{H}$ stretching vibration of the phenyl ring. The sharp intense absorption peak located at $1638 \mathrm{~cm}^{-1}$ was assigned to the $\mathrm{U}(\mathrm{C}=\mathrm{N})$ stretching as has been reported [13]. The band observed at $1270 \mathrm{~cm}^{-1}$ was attributed to $U$ (C-O) stretching.

\section{The U.V/visible spectra}

The electronic spectrum of the free ligand $(\mathrm{o}-\mathrm{OH}$ acetophenone hydrazone) exhibits two intense bands at 273 and $310 \mathrm{~nm}$ in DMSO as shown in Fig. 2.

\section{Emission and excitation spectra}

The fluorescence spectrum of the $\boldsymbol{o}$-hydroxy acetophenone hydrazone sol-gel matrix showed fluorescence emission at $\lambda_{\mathrm{em}} 425 \mathrm{~nm}$ as shown in Fig. 3 .<smiles>C/C(=N\N)c1ccccc1O</smiles>

Scheme 2: Structure of the ligand o-OH acetophenone hydrazone 


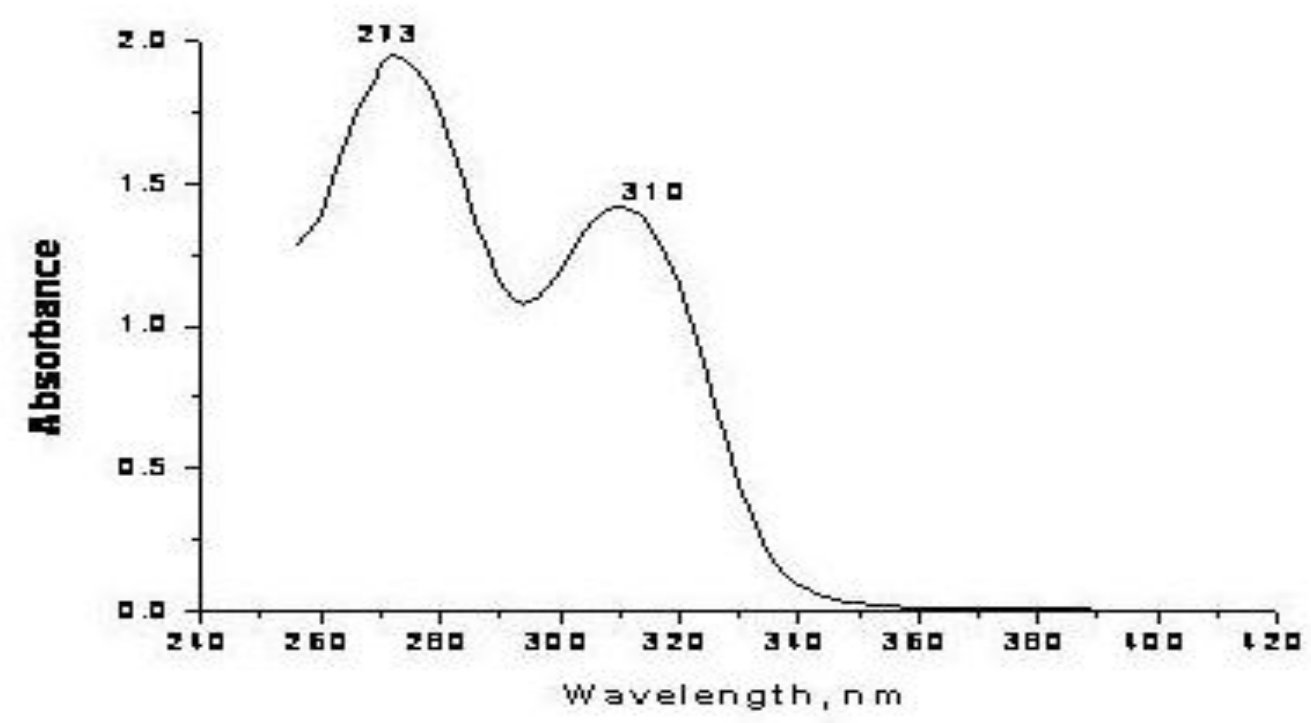

Fig. 2: The UV/ Visible spectra of o-OH acetophenone hydrazone.

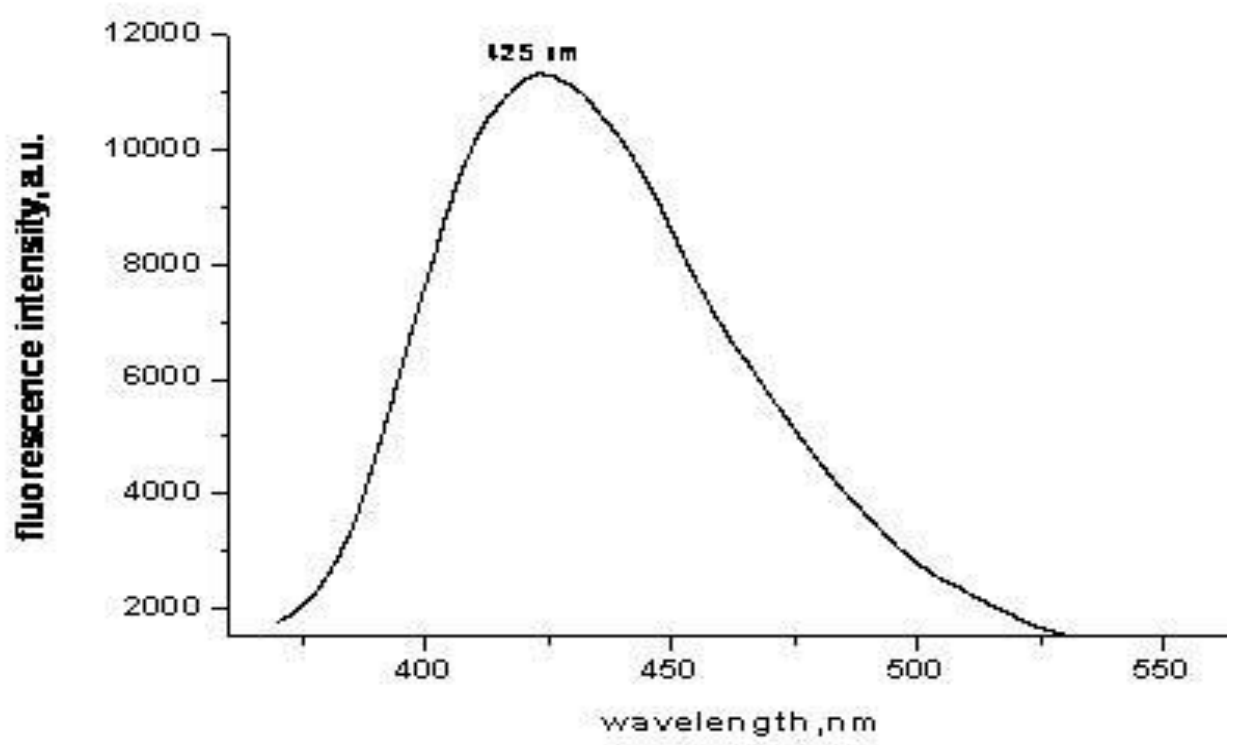

Fig. 3: The emission spectrum of the Ligand $\left(1 \times 10^{-3} \mathrm{~mol} / \mathrm{L}\right)$ at $\lambda_{\mathrm{ex}} / \lambda_{\mathrm{em}}=360 / 425 \mathrm{~nm}$.

\section{The Effect of pH on the fluorescence spectrum}

The $\mathrm{pH}$ of the medium has a large effect on the fluorescence intensity of the $\mathrm{o}-\mathrm{OH}$ acetophenone hydrazone in the range (3-10). The $\mathrm{pH}$ has been adjusted using $\mathrm{NH}_{4} \mathrm{OH}$ and $\mathrm{HCl}$, The suitable $\mathrm{pH}$ value where the peak at $425 \mathrm{~nm}$ has the highest intensity was at $\mathrm{pH} 10$.

\section{The Effect of solvents on the fluorescence spectrum}

The influence of the solvents on the fluorescence intensity of the ligand was studied; the results showed that the emission intensity was enhanced in the DMSO while a strong quenching effect was found in ethanol as shown in Fig. 4.

\section{Response of sensor to $\mathrm{Zn}^{2+}$ ion}

The chemical sensor exhibited remarkable fluorescence intensity enhancement upon exposure to $\mathrm{Zn}^{2+}$ ions. The nano optical sensor was placed in diagonal position in the quartz cuvette containing $2 \mathrm{~mL}$ buffer solution of $\mathrm{pH} 10$. The sample cell was titrated with microliter amounts of a concentrated $\mathrm{Zn}^{2+}$ ion solution, using a precalibrated micro pipette and the fluorescence intensity of the system was measured at $425 \mathrm{~nm}\left(\lambda_{\mathrm{ex}} 360 \mathrm{~nm}\right)$ after $5 \mathrm{~min}$ required to reach the equilibrium.

\section{Analytical performance}

1. Analytical parameters of the optical sensor

The six point's calibration curve as shown in Fig. 5 was obtained by plotting the peak intensity of the sensor at 
$\lambda_{\text {em }} 425 \mathrm{~nm}$ versus the concentration of $\mathrm{Zn}^{2+}$ ion and the graph was described by the regression equation:

$$
\mathbf{Y}=\mathbf{a}+\mathbf{b X}
$$

where $\mathrm{Y}=$ luminescence intensity of the optical sensor at $\lambda_{\mathrm{em}} 425 \mathrm{~nm} ; \mathrm{a}=$ intercept; $\mathrm{b}=$ slope and $\mathrm{X}=$ concentration in $\mathrm{nmol} \mathrm{mL}^{-1}$.

Regression analysis of luminescence intensity data using the method of least squares was made to evaluate the slope (b), intercept (a) and correlation coefficient (r) and the values were presented in Table 2 . The limit of detection (LOD) and quantitation (LOQ) calculated according to IUPAC guidelines ${ }^{[14]}$ using the formula:

\section{$\mathrm{LOD}=3.3 \mathrm{~S} / \mathrm{b}$ and $\mathrm{LOQ}=10 \mathrm{~S} / \mathrm{b}$}

where $\mathrm{S}$ is the standard deviation of blank luminescence intensity values and $b$ is the slope of the calibration plot, Table 2.

\section{Selectivity}

The selectivity behavior is obviously one of the most important characteristics of anion-selective optical sensor ${ }^{[15]}$, which is the relative optode response for the primary ion over other ions present in solution. In order to assess the possible analytical application of the sensing method, the effects of various ions on the determination of $\mathrm{Zn}^{2+}$ ion were examined. To evaluate the metal bonding property and selectivity, the competition experiments were also conducted by adding the interfering ions to solutions containing $2.0 \mu \mathrm{M}$ $\mathrm{Zn}^{2+}$ ion in Tris- $\mathrm{HCl}$ buffer, $\mathrm{pH}$ 8.0. The experiments were carried out by recording the change in the fluorescence intensity before $\left(\mathrm{F}_{\mathrm{o}}\right)$ and after adding the interfering ion at $2.5 \times 10^{3} \mathrm{~mol} \mathrm{~L}^{-1}$ level $(\mathrm{F})$ into $\mathrm{Zn}^{2+}$ ion solution. The resulting relative error $(\mathrm{RE})$ is defined as $\mathrm{RE}(\%)=\left[\left(\mathrm{F}-\mathrm{F}_{\mathrm{o}}\right) / \mathrm{F}_{\mathrm{o}}\right] \times 100$. The results of these tests on potential interferences are summarized in Fig. 6.
No significant interferences were observed if a less than $\pm 5 \%$ relative error was tolerated.

\section{Analytical applications}

To assess the applicability of the proposed sensor to real samples, an attempt was made to determine zinc ion in different human hair samples, collected under optimum conditions. Hair zinc levels of 9 healthy people between the 15 to 31 years age groups were examined with respect to age groups and their kind. As may be seen in Table 3 it was found that hair zinc levels of female group were higher than male group. Deficiency of this element appears to be more common in male than female due to requirements for zinc increase at puberty, particularly in boys, presumably associated with the high concentration of zinc present in the testes and accessory male sex glands. Our findings are in agreement with hair zinc levels reported in the literature ${ }^{[13]}$.

\section{Conclusion}

In conclusion, a novel sensor $o-\mathrm{OH}$ acetophenone hydrazone doped in sol-gel matrix for the determination of $\mathrm{Zn}^{2+}$ ions was developed, with good optical and mechanical properties. It has been shown that the response of this sensor in the presence of $\mathrm{Zn}^{2+}$ ions does not vary significantly in the $\mathrm{pH}$ range $8-10$. The optimal emission and excitation wavelengths of the sensor are examined in different solvents and it was found that maximum quantum yield was achieved in DMSO. The sensor shows a high selectivity and quick response for $\mathrm{Zn}^{2+}$ ion over other common metal ions. The proposed sensor has a wide dynamic range from of $1.0 \times 10^{-8}-2.0$ $\times 10^{-4} \mathrm{~mol} \mathrm{~L}^{-1}$ with a limit of detection (LOD) 3.72 $\times 10^{-9} \mathrm{~mol} \mathrm{~L}^{-1}$ and a regression coefficient of 0.993 . As a result, the developed sensor was successfully used in quantitative determination of $\mathrm{Zn}^{2+}$ ion with high accuracy in human hair samples.

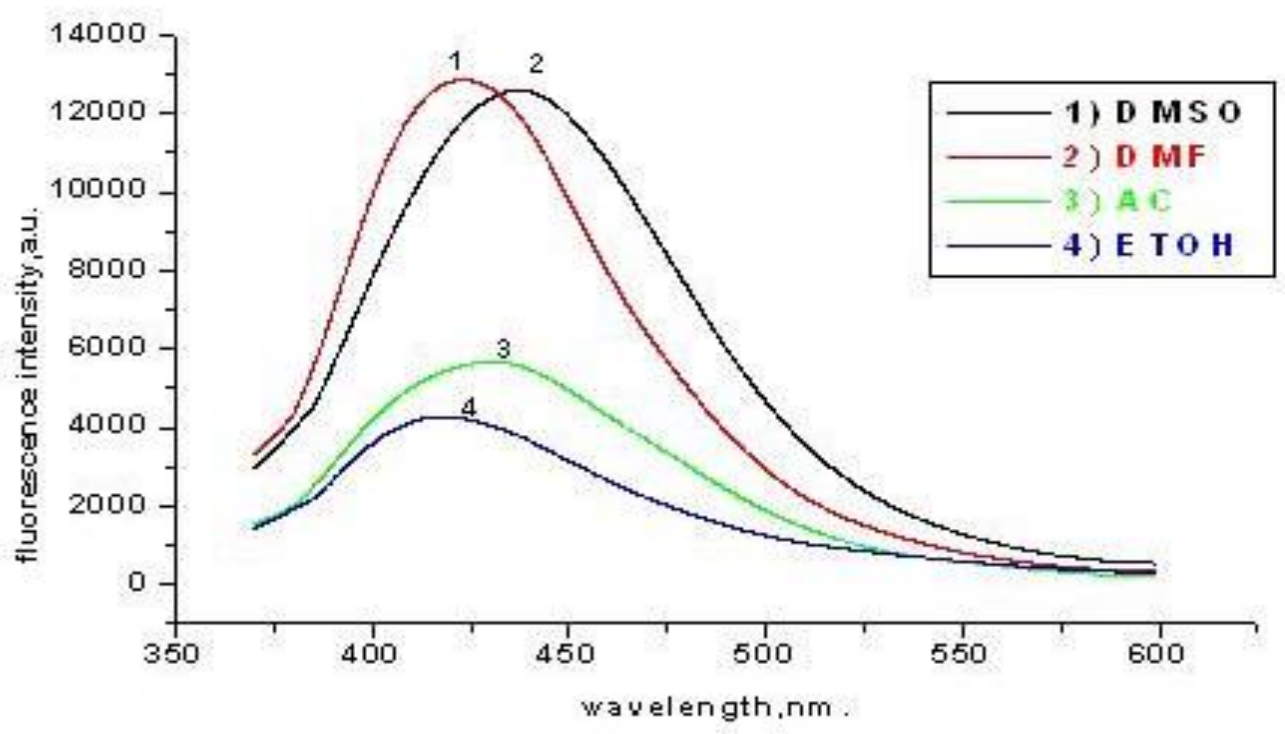

Fig. 4: The fluorescence spectra of the ligand $\left(1 \times 10^{-3} \mathrm{M}\right)$ in different solvents. 


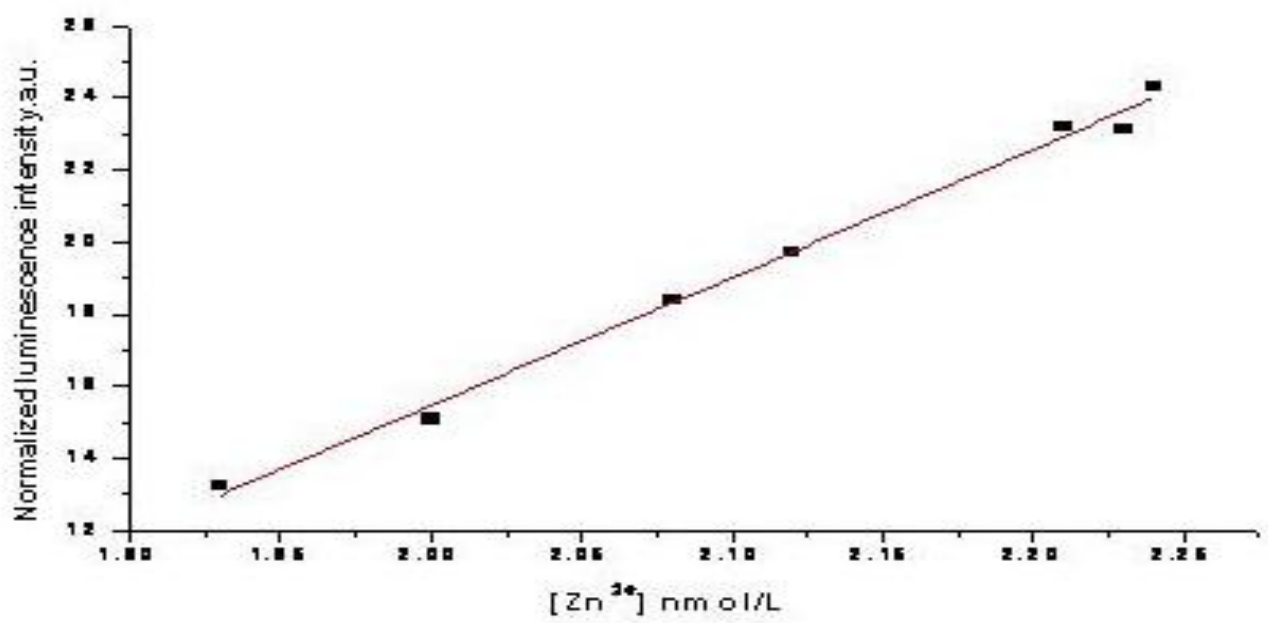

Fig. 5: Calibration curve of the luminescence intensity of the sensor (ligand) doped in sol gel matrix versus concentration of Zinc.

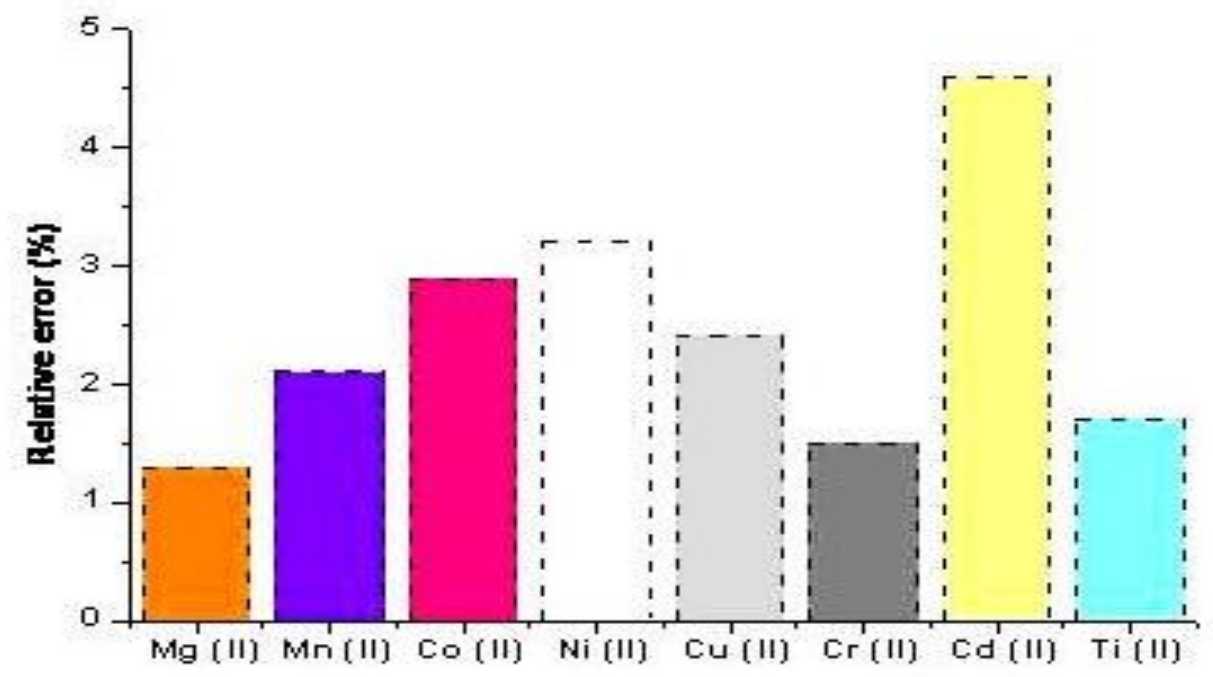

Fig. 6: Interferences of different metal ions $\left(2.5 \times 10^{3} \mathrm{~mol} \mathrm{~L}^{-1}\right)$ onto the fluorescence determination of $\mathrm{Zn}^{2+}$ ion (2.0 $\mu \mathrm{M}$ ) using the nano sensor at $\mathrm{pH} 7.0$.

Table 2: Sensitivity and regression parameters for the optical sensor.

\begin{tabular}{|c|c|}
\hline Parameter name & Parameter value \\
\hline$\lambda_{\text {em }}, \mathrm{nm}$ & 425 \\
\hline Linear range, $\mathrm{mol} \mathrm{L}^{-1}$ & $1.0 \times 10^{-8}-2.0 \times 10^{-4}$ \\
\hline${\text { Limit of detection (LOD), } \mathrm{mol} \mathrm{L}^{-1}}^{-9}$ & $3.72 \times 10^{-9}$ \\
\hline${\text { Limit of quantification (LOQ), } \mathrm{mol} \mathrm{L}^{-1}}^{-8}$ & $1.52 \times 10^{-8}$ \\
\hline Intercept (a) & 2.9 \\
\hline Slope (b) $\times 10^{9}$ & 1.4 \\
\hline Standard deviation $\times 10^{-3}$ & 1.73 \\
\hline Regression coefficient (r) & 0.993 \\
\hline
\end{tabular}


Table 3: Comparison of hair zinc levels of male and female groups.

\begin{tabular}{|c|c|c|c|}
\hline No. of participants & Age & Females & Males \\
\hline & & $\ddot{\mathrm{x}} \pm \mathrm{SD}$ & $\ddot{\mathrm{x}} \pm \mathrm{SD}$ \\
\hline 4 & $15 \mathrm{y}-20 \mathrm{y}$ & $\mathbf{1 8 3} \pm \mathbf{1 . 7}$ & $\mathbf{1 7 1} \pm \mathbf{0 . 9}$ \\
\hline 5 & $21 \mathrm{y}-31 \mathrm{y}$ & $\mathbf{1 4 3} \pm \mathbf{1 . 2}$ & $\mathbf{1 2 7} \pm \mathbf{1 . 1}$ \\
\hline
\end{tabular}

\section{References}

1) Abd El-Halim, H. F., Omar, M. M., Mohamed, G. G. and Sayed, M. A. (2011). Spectroscopic and biological activity studies on tridentate Schiff base ligands and their transition metal complexes. Europ. J. Chem., 2(2): 178-188.

2) Monfared, H. H., Pouralimardan, O. and Janiak, C. (2007). Synthesis and spectral characterization of hydrazone Schiff bases derived from 2,4dinitrophenylhydrazone. Crystal structure of salicylaldehyde-2,4-dinitrophenylhydrazone. Z. Naturforsch, 62b: 717-720.

3) Hambidge K. M. and Krebs N. F. (2007). Zinc Deficiency: A Special Challenge. J. Nutr., 137(4): 1101-1105.

4) Auld D. S. (2001). Zinc coordination sphere in biochemical zinc sites. Biometals, 14: 271-313.

5) Callender E. and Rice K. C. (2000). The urban environmental gradient: Anthropogenic influences on the spatial and temporal distributions of lead and zinc in sediments. Environ. Sci. Technol., 34: 232238.

6) Horvath A. L. (2009). Solubility of structurally complicated materials: 3. Hair. Sci. World J., 9: 255271.

7) Memon, A., Kazi, T. G., Afridi, H. I., Jamali, M. K., Arain, M. B., Jalbani, N. and Syed, N. (2007). Evaluation of zinc status in whole blood and scalp hair of female cancer patients. Clin. Chim. Acta, 379: $66-70$.

8) Schwarzenbach G., Flaschka $H$. and Irving $H$. (1969). Complexmetric Titrations, $2^{\text {nd }}$ Ed., Methuen,
London, 260.

9) Belal A., Zayed M. A., EL-Desawy M. and Rakha S. M. A. H. (2015). Structure investigation of three hydrazones Schiff's bases by spectroscopic, thermal and molecular orbital calculations and their biological activities. Spectrochim. Acta, 138: 49-57.

10) Attia M. S. and Abo Aly M. M. (2010). Highly sensitive and selective spectrofluorimetric determination of metoclopramide hydrochloride in pharmaceutical tablets and serum samples using $\mathrm{Eu}^{3+}$ ion doped in sol-gel matrix. Talanta, 82: 78-84.

11) Heinersdorff $N$. and Taylor T. G. (1979). Concentration of zinc in the hair of schoolchildren. Arch. Dis. Child., 54: 958-960.

12) Sporkert F. and Pragst F. (2000). Use of headspace solid-phase microextraction (HS-SPME) in hair analysis for organic compounds. Forensic Sci. Int., 107: $129-148$.

13) Singh V. P., Singh S., Singh D. P., Singh P., Tiwari K., Mishra M. and Butcher R. J. (2013). Synthesis, spectral and single crystal X-ray diffraction studies on $\mathrm{Co}(\mathrm{II}), \mathrm{Ni}(\mathrm{II}), \mathrm{Cu}(\mathrm{II})$ and $\mathrm{Zn}$ (II) complexes with o-amino acetophenone benzoyl hydrazone. Polyhedron, 56: 71-81.

14) Abdel Aziz A. A. (2013). A novel highly sensitive and selective optical sensor based on a symmetric tetradentate Schiff-base embedded in PVC polymeric film for determination of $\mathrm{Zn}^{2+}$ ion in real samples. $\mathrm{J}$. Luminescence, 143: 663-669.

15) Mawson C. A. and Fisher M. I. (1953). Zinc and carbonic anhydrase in human semen. Biochem. J., 55(4): 696-700. 